\title{
O TEXTO COMO PRETEXTO: LER OU NÃO LER, EIS A QUESTÃO!
}

\section{EL TEXTO COMO PRETEXTO: LEER O NO LEER, ¡ESA ES LA PREGUNTA!}

\author{
Márcia Quirino Ferreira Oliveira ${ }^{1}$
}

Recebido: 10 abr. 2019

Aceite: 7 jun. 2019

DOI https://doi.org/10.29327/2.1373.1-14

RESUMO: O presente trabalho visa a relatar a experiência de alunos e docentes durante um bimestre de atividades e a resultante apresentação na VI Semana da Leitura de uma instituição de Educação Básica. Pretendo descrever neste relato três das dez atividades realizadas com um grupo de alunos. $\mathrm{O}$ objetivo de cada atividade, vinculadas ao gênero conto, foi a promoção da prática de leitura e o desenvolvimento da capacidade leitora dos alunos no seu processo de ensinoaprendizagem. Como resultado da realização dessas atividades, percebe-se o envolvimento protagonista dos alunos, suas reflexões sobre a língua, o aguçamento do interesse pela leitura e os desenvolvimento de habilidades diversas. O viés interdisciplinar também foi contemplado nesta experiência, pois os mesmos contos foram usados por outros docentes em seus componentes curriculares. (FAZENDA, 1993).

PALAVRAS-CHAVE: Língua Portuguesa; Contos; Leitura.

RESUMEN: El presente trabajo tiene como objetivo informar acerca de la experiencia de los estudiantes y maestros durante un período de dos meses de actividades y la presentación resultante en la VI Semana de Lectura de una institución de Educación Básica. Tengo la intención de describir en este informe tres de las diez actividades realizadas con un grupo de alumnos. El objetivo de cada actividad, relacionada con el cuento de género, fue la promoción de la práctica de la lectura y el desarrollo de la capacidad de lectura de los estudiantes en su proceso de enseñanza y aprendizaje. Como resultado de estas actividades, se notan la participación de los estudiantes, sus reflexiones sobre el lenguaje, el interés en la lectura y el desarrollo de diferentes habilidades. El sesgo interdisciplinario también fue contemplado en esta experiencia, porque las mismas historias fueron utilizadas por otros maestros en sus componentes curriculares. (FAZENDA, 1993).

PALABRAS-CLAVE: Lengua Portuguesa; Cuentos; Lectura.

\footnotetext{
${ }^{1}$ Graduanda em Pedagogia na Universidade Virtual do Estado de São Paulo (UNIVESP). Docente no Instituto Federal de São Paulo (IFSP). E-mail: marcia.ferreira@ifsp.edu.br. ORCID iD https://orcid.org/0000-0001-7523-0052
} 


\section{INTRODUÇÃO}

O ensino de língua materna na educação básica é um assunto bastante desafiador tanto para o docente quanto para os alunos. Sendo a língua portuguesa sua língua materna, o alunado entende que não há necessidade de aprofundar no aprendizado dessa língua e tendem, assim, a não aceitar propostas novas, mais refinadas e mais complexas no desenvolvimento de competência em sua própria língua.

Esse cenário abriga o ensino de literatura que passa, no ensino médio, a ser sistematicamente desenvolvido a partir de referenciais teóricos e cronológicos das escolas literárias cujo objetivo reside na formação de um público leitor/escritor a partir do contato com textos que lhes é relevante. Nessa seara, exige-se do docente maior capacidade de constante autoajuste e reinvenção devido ao pouco interesse que é despertado nos alunos por meio das ementas dos cursos, e.g. técnicos integrados. Isso demanda do docente o uso de recursos metodológicos que propiciem um olhar diferenciado aos alunos e arrebatem seu interesse pelo aprendizado de sua língua materna e cultura.

O objetivo desta atividade é demonstrar como isso é possível na medida em que se dinamiza o ambiente de ensino-aprendizagem e se possibilita maior interação do aprendiz com a realidade social.

\section{DESCRIÇÃO DAS ATIVIDADES}

As atividades do presente relato ocorreram durante um bimestre letivo. Tudo começou a se desenhar no planejamento pedagógico de 2019 quando o corpo docente da instituição onde atuo discutiu a importância da leitura e formação de alunos leitores. Fomos unânimes no entendimento de que não seria produtivo para os alunos ingressantes na instituição que se lhes propusesse a leitura de clássicos supostamente exigidos em exames de entrada nas universidades brasileiras.

A partir dessa premissa, decidimos que os contos seriam um gênero apropriado para esse alunado e sua entrada no universo literário. Aos professores de Português coube a tarefa de, por 
meio de contos, diagnosticar o nível de proficiência leitora desses alunos ingressantes. Aos docentes de outros componentes curriculares caberia o trabalho com contos a partir dessa investigação inicial visando ao desenvolvimento desses alunos em sua habilidade de leitura.

Desafio lançado, contos escolhidos, leituras acontecendo todas as segundas-feiras, debates em sala, contextualização, reflexões, analogias, enfim, as aulas ganharam vida e cor - não eram mais consideradas como aulas chatas de leitura (MORICONI, 2001). O mesmo processo ocorreu nas aulas em outras disciplinas em que os contos eram usados por seus docentes.

Surge daí a proposta do título desse relato de experiência: usar o texto como pretexto para o desenvolvimento de habilidades e melhoria na capacidade leitora dos alunos, bem como a abordagem de assuntos teóricos constantes na ementa do curso. Meu entendimento é que o conhecimento do contexto (onde se ensina), dos alunos (a quem se ensina), de si mesmo (do docente), de como se ensina (a metodologia) e, por fim, o que se ensina (o conteúdo), são outros tipos de conhecimentos que merecem destaque e serem analisados constantemente. Neste sentido, concordo com Schulman quando o autor diz que:

[...] compreendendo as variações dos métodos e modelos de ensino pode-se ajudar os alunos em sua construção do conhecimento; e estando abertos para revisar seus objetivos, planos e procedimentos na medida em que se desenvolve a interação com os alunos. Esse tipo de compreensão não é exclusivamente técnica, nem somente reflexiva. Não é apenas o conhecimento do conteúdo, nem o domínio genérico de métodos de ensino. É uma mistura de tudo isso e é, principalmente pedagógico. (SCHULMAN, 1992, p. 12)

Em outras palavras, cabe ao professor identificar o que está envolvido no processo de ensino-aprendizagem e sua relação com a realidade para poder refletir pedagogicamente como proporcionar caminhos que promovam o ensino.

Atendendo ao pedido dos alunos, lemos o conto A Cartomante de Machado de Assis e, como consequência, muitos temas cotidianos vieram à tona em nossas conversas e debates em sala. Aproveitei, então, para usar esse material como pretexto para abordar os conceitos de linguagem verbal, não-verbal e multimodal. Como atividade de consolidação da proposta os alunos, em grupos, criaram um teatro não-verbal a partir do conto.

Em seguida, lemos, também de Machado de Assis, o conto O Pai contra Mãe. De temática 
forte para os adolescentes, esse conto foi usado como pretexto para que ele pudessem dissertar sobre temas como adoção e aborto. Essa leitura permitiu aos alunos produzirem textos com um nível de argumentação coerente com sua realidade social. Outros docentes também puderam usar o mesmo conto abordando-o sob diferentes visões e proporcionando novas contribuições aos alunos.

O pretexto para abordar o conceito de variações linguísticas, partiu da leitura do conto de João do Rio chamado O Bebê da Tarlatana Rosa. Em grupos, os alunos foram desafiados a recontar o conto desvinculados da norma culta. Fizeram isso produzindo teatro, uma paródia do conto em forma de rap e outra como funk, além de perfomances de dança.

A participação de todos os alunos nessas atividades resultou na participação de alguns na Semana de Leitura da escola.

\section{RESULTADOS}

Alguns alunos das turmas participantes, colocaram-se à disposição para apresentar uma comunicação oral na Semana de Leitura descrevendo as atividades supramencionadas. Produziram resumos dos contos e uma apresentação com a ajuda de um software. À professora coube-lhe a tarefa de mediar a apresentação dos alunos. Durante a comunicação, os alunos reproduziram as atividades realizadas em sala. O êxito das atividades foi perceptível pelo aumento do interesse dos alunos pelo aprendizado de língua portuguesa, pela melhora no envolvimento com as demais atividades da disciplina e maior cooperação entre si para a realização de todas as atividades.

Sobre a valorização da literatura, que é a premissa de todo este trabalho, ecoo Antonio Cândido:

Ora, se ninguém pode passar vinte e quatro horas sem mergulhar no universo da ficção e da poesia, a literatura concebida no sentido amplo a que me referi parece corresponder a uma necessidade universal, que precisa ser satisfeita e cuja satisfação constitui um direito. Alterando um conceito de Otto Ranke sobre o mito, podemos dizer que a literatura é o sonho acordado das civilizações. Portanto, assim como não é possível haver equilíbrio psíquico sem o sonho durante o sono, talvez não haja equilíbrio social sem a literatura. Deste modo, ela é fator indispensável de humanização e, sendo assim, confirma o homem na sua humanidade. (CÂNDIDO, 1989, p. 112) 


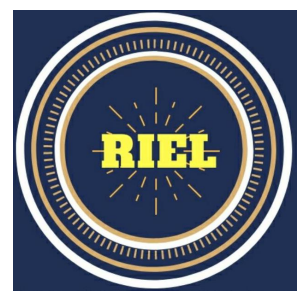

Arremato, assim, ressaltando que os estudantes tornaram-se paulatinamente protagonistas e não apenas observadores, interagiam e dialogavam entre si buscando soluções e melhorias para sua comunicação.

\section{CONSIDERAÇÕES FINAIS}

A princípio percebemos que as turmas, mostravam-se tímidas e curiosas com relação às apresentações das leituras que eram feitas em sala. Porém, a medida que as leituras aconteciam os discentes se desfizeram do estigma de que leitura na escola não é boa e que todo material indicado pelo professor de Português é chato. Passaram a conhecer, descobrir e desfazer preconceitos. Os contos eram baseados em suspense, finais arrebatadores, tristes constatações da realidade, cenas análogas a outras que nos induzem a reflexões e envolvimento com a sociedade.

Cabe destaque também o papel dos professores de biologia, sociologia, filosofia, e outros, que se valiam dos contos para abordar temas em comum com suas aulas. Desse modo, junto com o docente de língua portuguesa, aplicavam as diretrizes contidas nos PCNs sobre a realidade discente.

Cada aula com uma matéria diferente percebia-se a motivação, o aprendizado, um novo olhar, a conquista e a superação. Inegável o beneficio que o exercício interdisciplinar proporciona:

A interdisciplinaridade não dilui as disciplinas, ao contrário, mantém sua individualidade. Mas integra as disciplinas a partir da compreensão das múltiplas causas ou fatores que intervêm sobre a realidade e trabalha todas as linguagens necessárias para a constituição de conhecimentos, comunicação e negociação de significados e registro sistemático dos resultados. (PCN/EM, 2002, p. 89).

É importante enfatizar que a interdisciplinaridade supõe um eixo integrador, que pode ser o objeto de conhecimento, um projeto de investigação, um plano de intervenção. Nesse sentido ela deve partir da necessidade sentida pelas escolas, professores e alunos de explicar, compreender, intervir, mudar, prever, algo que desafia uma disciplina isolada e atrai a atenção de mais de um olhar, talvez vários. Explicação, compreensão, intervenção são processos que requerem um conhecimento que vai alem da descrição da realidade mobiliza competências cognitivas para deduzir, tirar inferências ou fazer previsões a partir do fato observado. (PCN/EM, 2002, pp. 88, 89).

Desse modo, essa proposta contribui para o desenvolvimento profissional dos docentes 
envolvidos nela, pois reforça o compromisso com o desenvolvimento e aprendizado dos alunos.

Em conclusão, espero que as atividades brevemente relatadas aqui sirvam de combustível para outras e melhores práticas que visem ao beneficio de nossos alunos por um viés interdisciplinar apesar de seus constragimentos e complexidade.

\section{REFERÊNCIAS}

BRASIL. Ministério da Educação. Secretaria de Educação Média e Tecnológica. Parâmetros Curriculares Nacionais: Ensino Médio. Brasília: Ministério da Educação, 2002.

SCHULMAN, L. Renewing the pedagogy of teacher education: the impact of subject specific conceptions of teaching. Simpósio sobre Didáticas Específicas en la Formación de Professores. Santiago de Compostela, 1992.

FAZENDA, I. A interdisciplinaridade: um projeto em parceria. São Paulo: Loyola, 1993.

CÂNDIDO, A. Vários escritos. 44 ed. São Paulo: Duas Cidades, 2004.

MORICONI, I. Os cem melhores contos do século XX. São Paulo: Editora Objetiva, 2001. 